\title{
Synthesis of poly(vinyl alcohol)-graft-poly(e-caprolactone) and poly(vinyl alcohol)-graft-poly(lactide) in melt with magnesium hydride as catalyst
}

\author{
Nadia Guerrouani, André Mas*, François Schué
}

UMR 5253 CNRS-UM2-ENSCM-UM1, Institut Charles Gerhardt Montpellier, Equipe IAM/SOM, Place Eugène Bataillon, 34095 Montpellier Cedex 5, France

Fax : 33-(0)467144028 ; E-mail : Andre.Mas02@univ-montp2.fr

Keywords : graft polymer; poly(ع-caprolactone); polylactide; poly(vinyl alcohol).

\begin{abstract}
Grafting of poly( $\varepsilon$-caprolactone) (PCL) and poly(lactide) (PLA) chains on poly(vinyl alcohol) backbone (PVA degree of hydrolysis 99\%) was investigated using $\mathrm{MgH}_{2}$ environmental catalyst and melt-grown ring opening polymerization (ROP) of $\varepsilon$-caprolactone (CL) and Llactide (LA), that avoiding undesirable toxic catalyst and solvent. The ability of $\mathrm{MgH}_{2}$ as catalyst as well as yield of reaction were discussed according to various PVA / CL / $\mathrm{MgH}_{2}$ and PVA / LA / $\mathrm{MgH}_{2}$ ratio. PVA-g-PCL and PVA-g-PLA were characterized by ${ }^{1} \mathrm{H}$ and ${ }^{13} \mathrm{C}$ NMR, DSC, SEC, IR. For graft copolymers easily soluble in tetrahydrofuran (THF) or chloroform, wettability and surface energy of cast film varied in connection with the length and number of hydrophobic chains. Aqueous solution of micelle-like particles was realized by dissolution in THF then addition of water. Critical micelle concentration (CMC) decreased with hydrophobic chains.
\end{abstract}




\section{INTRODUCTION}

In the past few years, many research works have been devoted to the synthesis of well-defined structure like block, comb or star polymers based on biocompatible and biodegradable aliphatic polyesters. The control of the macromolecular structure led to versatile polymers with optimized chemical, physical and mechanical properties. Such polymers have been mainly developed in biomedical and pharmaceutical fields for gel development and tissue engineering. ${ }^{1}$ Further applications could be as plasticizers and compatibilizing agents for industrial polymers and packaging materials. ${ }^{2}$ By increasing the production and uses of materials from such polymers, the necessity to safeguard our environment became a target for further development of green chemistry. Thus, it became essential to optimize the synthesis of each polymer and especially to get rid of the undesirable toxic molecules as catalysts and solvents because complete removal of residue from the solid is quite impossible. New catalysts as well as bulk and melt polymerization process need to be developed.

Aliphatic polyesters such as poly(e-caprolactone) (PCL) and poly(lactide) (PLA) were first synthesized from anionic or coordination-insertion ring opening polymerization (ROP) of monomers in presence of alkali metals or organometallic compounds, carboxylates and alkoxides as typical and effective initiators. ${ }^{3-5}$ Non toxic $\mathrm{Ca}, \mathrm{Fe}$ and $\mathrm{Mg}$ based catalysts or coinitiator are preferable. Recently, ROP was investigated for example in the presence of calcium alkoxide, ${ }^{6}$ ferric alkoxide ${ }^{7}$ ferrous acetate ${ }^{8}$ and natural amino acids ${ }^{9}$ considering that the biocompatibility and in vivo safety of thus-obtained polymers must be satisfying for medical and pharmaceutical purpose.

Amphiphilic diblock and triblock copolymers were synthesized from hydrophilic mono or $\alpha, \omega$-dihydroxy-poly(ethylene oxide) (PEO) used as initiator. The hydrophobic polyester block(s) resulted from ROP of $\varepsilon$-caprolactone (CL), $\beta$-butyrolactone (BL), glycolide (GL) and lactide (LA). Among the various catalysts ( $\left.\mathrm{SnO}, \mathrm{PbO}, \mathrm{GeO}_{2}, \mathrm{SnCl}_{2} \ldots\right)$ experienced to prepare the PEO based-initiator, ${ }^{10,11} \mathrm{Zn}{ }^{12}$ and calcium ammoniate ${ }^{13}$ seem to be the least toxic. However, the one most commonly catalyst used was the commercially stannous 2ethylhexanoate or stannous octoate $\left(\mathrm{Sn}(\mathrm{Oct})_{2}\right)$ because it allowed to high polymerization rate and it was accepted by the Food and Drug Administration. ${ }^{14}$ However the cytotoxycity of $\mathrm{Sn}(\mathrm{Oct})_{2}$ against a broad variety of microorganisms is undesirable when tin salt is present as 
impureties in polymers designed for medical or pharmaceutical applications. ${ }^{15}$

Branched and star-shaped polymers were prepared by using alcohols with different numbers of hydroxyl groups as initiators and to date, $\mathrm{Sn}(\mathrm{Oct})_{2}$ was used as catalyst. Polyester based structures growing from glycerol, pentaerythrol, polyglycerine ${ }^{16}$ and dipentaerythrol ${ }^{17}$ have been described. It was suggested that high hydroxyl content, like in multi-hydroxyl functional polymers, should accelerate polymerization of lactone and lactide by increasing the number of growing chains. Multi-hydroxyl functional backbones offer also the possibility of building different architectures, therefore the physicochemical properties such as hydrophilichydrophobic balance could be controlled by the type and amount of backbone used. Recently a novel synthetic method was developed by the use of poly(L-lactide) (PLLA) extended chains resulting from the hydrolytic degradation of PLLA crystallized films. Extended chains are anticipated to act as a initiator system with $\mathrm{Sn}(\mathrm{Oct})_{2}$ because they have many hydroxyl groups. ${ }^{18}$

Typical and interesting architectures are comb-like branched polyesters. Little is known about the synthesis and the properties of such copolymers. Poly(vinyl alcohol) (PVA) backbone was used as macro-initiator for ROP of CL and LA in solution in the presence of $\mathrm{Sn}(\mathrm{Oct})_{2}$. The choice of non toxic polymerization solvents is strongly limited because of the poor solubility of PVA, except in water. The ring-opening oligomerization of CL with PVA was examined in an aqueous solution at $120{ }^{\circ} \mathrm{C},{ }^{19}$ however, no graft copolymer was obtained. PVA-graft-PCL (PVA-g-PCL) and PVA-graft-PLA (PVA-g-PLA) were synthesized in dimethylsulfoxide (DMSO) ${ }^{19}$ and in N, N'-dimethylformamide (DMF)/toluene solvent system respectively ${ }^{20}$. PVA-g-PLA was also synthesized via ring-opening melt polymerization. For this, PVA (molecular weight 10.000-15.000 and degree of hydrolysis 80-88 \%), $\operatorname{Sn}(\mathrm{Oct})_{2}$, L-lactide or D,L-lactide were mixed at $130{ }^{\circ} \mathrm{C}$ and clear melt was obtained by the authors. ${ }^{21}$ Possible dissolution of PVA in monomer was probably due to the residual non hydrolyzed acetate groups (12-20\%) in backbone material. Patents on the preparation of similar graft copolymers by bulk or melt polymerization have been already published, however no clear description of the process was done. ${ }^{22,23}$

Synthesized PVA-g-PCL and PVA-g-PLA continue to receive increasing interest particularly in biomedical sector. Amphiphilic comb copolymers can self-disperse in certain solvents 
which are good solvents for backbone and poor solvents for graft chains. A combination between PVA, PCL and PLA chains is attractive in terms of the formation of spherical nonionic micelles and hydrogels for applications in encapsulation and drug delivery systems.

In the present paper, we report the melt-grown synthesis of PVA-g-PCL and PVA-g-PLA from PVA totally hydrolyzed, using magnesium hydride $\left(\mathrm{MgH}_{2}\right)$ as a new catalyst for the preparation of PVA based-initiator for ROP of lactone and lactide. $\mathrm{MgH}_{2}$ was selected because magnesium is involved in human metabolism and it is an environmental metal. Thus, it was supposed that non toxic impurities were left in the copolymer. The objective of our research is to show the efficiency of $\mathrm{MgH}_{2}$ and to characterize the chemical structure of the graft copolymers by changing the polymerization conditions. In addition, to demonstrate the amphiphilic character of synthesized copolymers we investigated the hydrophilichydrophobic surface properties of copolymer cast films and the preparation of micelle-like particles in aqueous solution.

\section{EXPERIMENTAL}

\section{Materials}

Poly(vinyl alcohol) (PVA) (molecular weight $\mathrm{M}_{\mathrm{w}}=41000 \mathrm{~g} \mathrm{~mol}^{-1}, \mathrm{M}_{\mathrm{n}}=28000 \mathrm{~g} \mathrm{~mol}^{-1}$, degree of hydrolysis $99 \%$ ) dissolved with heat in lactone and lactide monomers. Dissolution was strongly dependent on the monomer / PVA ratio and was improved by addition of dimethyl sulfoxyde (DMSO). PVA was rigorously dried at $100{ }^{\circ} \mathrm{C}$ in vacuo for at least $6 \mathrm{~h}$. $\varepsilon$ caprolactone (CL, bp $96-97.5{ }^{\circ} \mathrm{C} / 10 \mathrm{~mm} \mathrm{Hg}$ ) was dried on $\mathrm{CaH}_{2}$ and distilled. L-Lactide (LA, mp 92-94 ${ }^{\circ} \mathrm{C}$ ) was purified by crystallization from dried toluene then sublimate. Chiral L-LA monomer was selected for current investigation into the stereochemistry of the polymerization. Complete results will be published shortly. In this article, polylactide block is called PLA without reference to the possible stereoregularity of the polymer chain. Dimethyl sulfoxyde (DMSO) was dried under $\mathrm{CaH}_{2}$ and purified by repeated distillation under reduced pressure over $\mathrm{CaH}_{2}$. Magnesium hydride $\left(\mathrm{MgH}_{2}\right)$ was used as received. X-rays analysis of dry $\mathrm{MgH}_{2}$ revealed the presence of following elements (in at \%, after deducting oxygen from analysis under air): $\mathrm{Mg}$ 99.38, Ca 0.1, Al 0.38, Si 0.12, Fe 0.01. PVA, monomers, DMSO and $\mathrm{MgH}_{2}$ were stored under argon. All chemicals were provided by Sigma-Aldrich.

\section{Measurements}


${ }^{1} \mathrm{H}$ and ${ }^{13} \mathrm{C}$ NMR were recorded in $\mathrm{CDCl}_{3}$ or DMSO $\mathrm{d}_{6}$ at $25{ }^{\circ} \mathrm{C}$ with a Bruker spectrometer at 400 and $100 \mathrm{MHz}$ respectively. Chemical shifts are given in ppm downfield from TMS. Differential Scanning Calorimetry (DSC) was carried out with a Metler DSC 30 instrument in sealed aluminium pans under nitrogen atmosphere. The heating rate was $10{ }^{\circ} \mathrm{C} / \mathrm{min}$, profils covered a range from -100 to $250{ }^{\circ} \mathrm{C}$. Size exclusion chromatography (SEC) was performed on Waters HR3, HR4 and HR5 columns with Waters 515 pump, Waters 2410 RI detector, eluent chloroform, flow rate $0.5 \mathrm{~mL} / \mathrm{min}$. FTIR spectra were recorded with a Perkin Elmer 100 spectrometer. Cast films were prepared from 5-10 \% w/w solution of copolymers in THF. Contact angles of cast films were measured $5 \mathrm{~s}$ after the drop was deposited with a Kruss G1 apparatus. Surface energy $\left(\gamma_{\mathrm{s}}\right)$, dispersive $\left(\gamma_{\mathrm{s}}{ }^{\mathrm{d}}\right)$ and polar $\left(\gamma_{\mathrm{s}}^{\mathrm{p}}\right)$ components were calculated with the Owens and Wendt method using water and diiodomethane. ${ }^{24}$

The following equations were used:

$$
\begin{gathered}
(1+\cos \theta) \gamma_{1}=2\left(\gamma_{s}{ }^{d} \gamma_{1}{ }^{d}\right)^{1 / 2}-2\left(\gamma_{s}^{p} \gamma_{1}{ }^{p}\right)^{1 / 2} \\
\gamma_{s}=\gamma_{s}{ }^{d}+\gamma_{s}^{p}
\end{gathered}
$$

( $\theta$ contact angle with water or diiodomethane, surface tension, polar and dispersive components for water: $\gamma_{1}=72.8 \mathrm{~mJ} \mathrm{~m}^{-2}, \gamma_{1}^{\mathrm{p}}=51.0 \mathrm{~mJ} \mathrm{~m}^{-2}, \gamma_{1}^{\mathrm{d}}=21.8 \mathrm{~mJ} \mathrm{~m}^{-2}$ and for diiodomethane: $\gamma_{1}=\gamma_{1}{ }^{\mathrm{d}}=44.6 \mathrm{~mJ} \mathrm{~m}^{-2}$.

Micelle-like particles in aqueous solutions of copolymers were prepared by slow addition, dropwise, of doubly distilled water into THF solutions of copolymers with stirring. THF was slowly removed using a rotary evaporator at $25^{\circ} \mathrm{C}$ for $2 \mathrm{~h}$. CMC was deduced from the graph of surface tension $\left(\mathrm{mJ} \mathrm{m}^{-2}\right)$ of aqueous solution of copolymers versus the polymer concentration $(\log \mathrm{C} g / \mathrm{L})$. Surface tensions were measured at $25{ }^{\circ} \mathrm{C}$ with a Lauda tensiometer. Surface tension decreased with increasing the concentration below CMC and it is nearly constant above CMC. CMC was then taken as the change in slope of the graph.

\section{Synthesis of poly(vinyl alcohol)-g-poly(e-caprolactone)}

Weighing out of chemicals and synthesis were run in a glove box to avoid humidity and oxygen traces. As an illustrative example, PVA grinded to a powder with a pestle (PVA unit $3.15 \mathrm{mmol}, 0.1386 \mathrm{~g})$, CL (13.88 mmol, $1.582 \mathrm{~g})$ and finely powdered $\mathrm{MgH}_{2}(0.2 \mathrm{mmol}$, $0.0052 \mathrm{~g}$ ) were introduced in a round-bottomed flask $(50 \mathrm{ml})$ equipped with an efficient bar magnet. The mixture was slowly stirred for $2 \mathrm{~h}$ at ambient temperature and degassed in vacuo. 
The flask was kept under dry argon and immersed in a silicone oil bath at $150{ }^{\circ} \mathrm{C}$ for about 16 h. Chloroform was added to complete dissolution of crude product (one night under stirring) and to separate non reacted PVA. Solution was poured down slowly in methanol (two times). Precipitated copolymer was collected by filtration and dried in vacuo at ambient temperature. Yield in copolymer was dependent on continuous stirring of reaction mixture and heating time. High viscosity was noticed after $2 \mathrm{~h}$ and yield was optimized by heating up to $36 \mathrm{~h}$. However for some feed compositions, the mixture was slightly brownish because of thermal degradation of non reacted PVA and PVA backbone of the copolymer. Some attempts were done to lower the temperature. A strongly reduced colouration or even no colouration was noticed at $110{ }^{\circ} \mathrm{C}$ under argon but yield was cut down by 20-30 \% .

\section{Synthesis of poly(vinyl alcohol)-g-polylactide}

Same general procedure as described above was used. Some modifications were required because of the limited dissolution of PVA in melt LA at $150{ }^{\circ} \mathrm{C}$, particularly for LA / PVA ratio smaller than about 7 (in mmol, or 23 in weight). As an illustrative example, PVA grinded to a powder with a pestle (PVA unit $1.05 \mathrm{mmol}, 0.0462 \mathrm{~g}$ ), LA (13.88 mmol, $1.998 \mathrm{~g}$ ) and finely powdered $\mathrm{MgH}_{2}(0.2 \mathrm{mmol}, 0.0052 \mathrm{~g})$ were introduced in a round-bottomed flask $(50 \mathrm{ml})$ equipped with an efficient bar magnet. The mixture was slowly stirred for $2 \mathrm{~h}$ at ambient temperature and degassed in vacuo. The flask was kept under dry argon and immersed in a silicone oil bath at $175^{\circ} \mathrm{C}$ for 30 min to obtain a clear melt, then at $150{ }^{\circ} \mathrm{C}$ for about $16 \mathrm{~h}$. The crude copolymer was purified by dissolution in chloroform and precipitation in methanol, solid product was dried in vacuo at room temperature. By heating up to $36 \mathrm{~h}$, yield was lightly increased but browning of the solid appeared. For every $10{ }^{\circ} \mathrm{C}$ decrease in reaction temperature, colouration gets down gradually. $110^{\circ} \mathrm{C}$ temperature led to high drop in yield but absence of colouration. Addition of DMSO resulted in more easy dissolution of PVA in small amounts of melt LA and ensured good yield for the graft copolymerization. PVA (4.54 mmol, $0.2 \mathrm{~g}$ ) and LA (3.47 mmol, $0.5 \mathrm{~g})$ were heated at $100{ }^{\circ} \mathrm{C}$, DMSO (12.8 mmol, $1 \mathrm{ml})$ then $\mathrm{MgH}_{2}(0.38 \mathrm{mmol}, 0.01 \mathrm{~g})$ were added. The flask was heated at $150{ }^{\circ} \mathrm{C}$ for about $16 \mathrm{~h}$. Dissolution and precipitation of the product followed the same above procedure. Particular care was needed to eliminate DMSO totally from solid copolymer by prolonged drying in vacuo at mild temperature.

\section{Determination of conversion $\%$ of monomers}


Experiments were conducted for example with PVA $1.13 \mathrm{mmol}$, CL $10.41 \mathrm{mmol}, \mathrm{MgH}_{2} 0.38$ mmol at $150{ }^{\circ} \mathrm{C}$ (run 5 Table 1). Samples from crude products of PVA-g-PCL were analyzed by ${ }^{1} \mathrm{H}$ NMR. The time-dependence was followed by the appearance of the methine proton signal of the grafting linkage PVA-CH $2-\mathrm{C}$-OCO-PCL at $5.08 \mathrm{ppm}$. Imprecise NMR identification of CL and PVA signals in crude products led to very rough determination of non reacted amounts and monomer conversion therefore. Crude products were dissolved and precipitated then yield in \% weight was determinate. NMR analyses of copolymer were done for each sample with about $15 \mathrm{mg}$ of copolymer in $1 \mathrm{ml} \mathrm{CDCl}_{3}$. A better estimate of conversion $\%$ of $\mathrm{CL}$ was obtained by comparing the intensity of methine proton signal and weight $\%$.

Same procedure was followed for PVA-g-PLA: PVA $1.05 \mathrm{mmol}$, LA $13.88 \mathrm{mmol}, \mathrm{MgH}_{2} 0.2$ mmol at $150{ }^{\circ} \mathrm{C}$ (run 3 Table 2). The time-dependence was followed by the appearance of the methine proton signal of the grafting linkage PVA- $\mathrm{CH}_{2}-\mathrm{C}$ H-OCO-PLA at $5.35 \mathrm{ppm}$ and the disappearance of the methine proton signal of non reacted LA at $5.10 \mathrm{ppm}$.

\section{Determination of degree of substitution and degree of polymerization}

Experimental degree of substitution $\left(\mathrm{DS}_{\mathrm{exp}}\right)$ of PVA backbone by PCL grafted chains and experimental degree of polymerization $\left(\mathrm{DP}_{\exp }\right)$ of $\mathrm{PCL}$ grafted chains were estimated from ${ }^{1} \mathrm{H}$ NMR spectra by equation (1) and (2):

$$
\mathrm{DS}_{\exp }=2 \mathrm{I}_{5.08} /\left(\mathrm{I}_{1.2-1.8}-3 \mathrm{I}_{2.30}\right) \quad \text { (1) } \quad \mathrm{DP}_{\exp }=\mathrm{I}_{2.30} / \mathrm{I}_{2.65}
$$

Theoretical degree of substitution $\left(\mathrm{DS}_{\mathrm{th}}\right)$ and theoretical degree of polymerization $\left(\mathrm{DP}_{\mathrm{th}}\right)$ were estimated by equation (3) and (4):

$$
\mathrm{DS}_{\mathrm{th}}=2\left[\mathrm{MgH}_{2}\right] /[\mathrm{PVA} \text { units }] \quad \text { (3) } \quad \mathrm{DP}_{\mathrm{th}}=[\mathrm{CL}] / 2\left[\mathrm{MgH}_{2}\right]
$$

For PVA backbone grafted by PLA chains, equations are following:

$$
\begin{gathered}
\mathrm{DS}_{\exp }=\mathrm{I}_{5.40} /\left(\mathrm{I}_{5.40}+\mathrm{I}_{3.86}\right)=2 \mathrm{I}_{5.40} /\left[\mathrm{I}_{1.1-1.7}-3\left(\mathrm{I}_{5.16}+\mathrm{I}_{4.20}\right)\right] \\
\mathrm{DP}_{\exp }=\left(\mathrm{I}_{5.16}+\mathrm{I}_{4.20}\right) / \mathrm{I}_{4.20}
\end{gathered}
$$


Mn of the copolymer was estimated by equation (8):

$$
\mathrm{M}_{\mathrm{n}}=\mathrm{M}_{\mathrm{nPVA}}+\left[\left(\mathrm{M}_{\mathrm{m} . \mathrm{u}} \times \mathrm{DP}_{\mathrm{exp}}\right)\left(\mathrm{DS}_{\mathrm{exp}} \times \mathrm{M}_{\mathrm{nPVA}} / 44\right)\right]
$$

with $\mathrm{M}_{n \text { PVA }}$ number molecular weight of PVA and $\mathrm{M}_{\text {m.u }}$ molecular weight of monomer unit $\mathrm{CO}\left(\mathrm{CH}_{2}\right)_{5} \mathrm{O}-$ or - $\mathrm{COCH}\left(\mathrm{CH}_{3}\right) \mathrm{O}$ -

PCL and PLA weight \% were estimated by equation (9) and (10):

$$
\begin{gathered}
\mathrm{M}_{\mathrm{w} \text { of PCL or PLA }}=\mathrm{DS}_{\exp } \times \mathrm{DP}_{\exp } \times \mathrm{M}_{\mathrm{m} . \mathrm{u}} \times \mathrm{M}_{\mathrm{w} \text { PVA }} / 44 \\
\mathrm{w} \%=\mathrm{M}_{\mathrm{w} \text { of PCL or PLA }} / \mathrm{M}_{\mathrm{w} \text { PVA }}+\mathrm{M}_{\mathrm{w} \text { of PCL or PLA }}
\end{gathered}
$$

\section{RESULTS AND DISCUSSION}

The control of hydrophilic-hydrophobic balance of graft PVA is required to promote recent applications. For environmental considerations, PCL and PLA chains were selected to be grafted by ROP of CL and LA using a clean melt process with non toxic $\mathrm{MgH}_{2}$ catalyst. To investigate the possibility for $\mathrm{MgH}_{2}$ to catalyst the reaction and to allow the control of the copolymer structure in such conditions, runs with various PVA / CL / $\mathrm{MgH}_{2}$ and PVA / LA / $\mathrm{MgH}_{2}$ ratios have been carried out.

\section{Influence of the monomer / PVA ratio on the melt-grown synthesis of copolymers}

Reaction and yield in copolymers were strongly dependent on the ability of PVA to melt or dissolve in monomer to give a system with suitable viscosity. The monomer / PVA ratio equal to about 5 at least gave a limpid solution of PVA in monomer and high yield in graft copolymer (run 1,2,4-6 Table 1 and run 1-3,9,10 Table 2). For CL / PVA and LA / PVA ratios smaller, system was not homogeneous enough and yield was lower (runs 3, 7-10 Table 1 and 4-8 Table 2).

Conversion of CL and LA was followed for limpid solutions. Conversion rose to about $60 \%$ for $16 \mathrm{~h}$ before the reaction mixture became very thick. The reactivity of LA was slightly higher than $\mathrm{CL}$ as shown by the representative curves for copolymerization of monomers in 
same conditions (Figure 1). Since active species operating in CL and LA polymerization in this system should be structurally identical, the monomer reactivity seems to be related to the monomer ring size. The larger reactivity of 6-membered L-lactide than 7-membered $\varepsilon$ caprolactone was already shown for bulk homopolymerization. ${ }^{25}$

Yield could be slightly increased by maintaining heating cautiously to avoid partial degradation of PVA and copolymers leading to a browning of the mixture as detailed in experimental part. It is well known that PVA is sensitive to thermal degradation in molten and solid state which consisted of water elimination and chain scission via a 6-membered transition state leading to the formation of volatile products including saturated and unsaturated aldehydes and ketones. ${ }^{26}$ A weight loss of $30 \%$ was recorded on PVA samples after 4 days at $180{ }^{\circ} \mathrm{C}$ under argon. ${ }^{27}$

The addition of DMSO in the feed improved the limpidity of mixture at $150{ }^{\circ} \mathrm{C}$ leading to good yield (runs 11-14 Table 1 and 11-14 Table 2). However toxicity of solvent has not to be neglected because solvent was present at the time of synthesis and in copolymer as residues.

\section{Spectrometric characterization of copolymers}

Poly(vinyl alcohol)-g-poly(E-caprolactone)

The occurrence of grafting was shown by the appearance of the signal at $5.08 \mathrm{ppm}$ in ${ }^{1} \mathrm{H}$ NMR spectra due to the methine proton of the linkage between PVA backbone and PCL side chains ( $\alpha$ in Figure 2). ${ }^{19,28}$ The methine proton of non grafted PVA units ( $\gamma$ partially superimposed in Figure 2) is situated at $4.14 \mathrm{ppm}$. The signals of the methylene protons of the PVA backbone ( $\beta, \delta$ in Figure 2$)$ and those of the 3 methylene protons groups central to $\mathrm{CL}$ units of PCL chains (b, c, d in Figure 2) are situated between 1.2 and 1.8 ppm. The protons of methylene groups linked to carbonyl (a in Figure 2) or oxygen (e in Figure 2) of ester groups of PCL chains are shifted to 2.30 and $4.08 \mathrm{ppm}$ respectively. Terminal methylene protons close to hydroxyl group of PCL chains ( $f$ in Figure 2) is situated at $3.65 \mathrm{ppm}$.

Grafting was confirmed by ${ }^{13} \mathrm{C}$ NMR mainly from the analysis of methine and methylene carbon signals of backbone chain. The formation of ester linkage resulted in small shift of methine carbon from $64.5 \mathrm{ppm}$ for non grafted to 66.3-68.3 ppm for grafted repeating units $(\gamma$ and $\alpha$ in Figure 3). ${ }^{19,29}$ Methylene carbon near the ester linkage appeared at $42.5 \mathrm{ppm}$ while the methylene carbon near the hydroxylated carbon group in non grafted PVA units was located at 44.0-46.5 ppm ( $\beta$ and small broad peak $\delta$ in Figure 3). Complete assignment was done in Figure 3. 
Characteristics absorption bands in FTIR spectra were situated at $3444 \mathrm{~cm}^{-1}\left(v_{\mathrm{OH}}\right), 2947 \mathrm{~cm}^{-1}$, $2866 \mathrm{~cm}^{-1}\left(v_{\mathrm{CH}}\right), 1727 \mathrm{~cm}^{-1}\left(v_{\mathrm{OC}=\mathrm{O}}\right)$ and $1097 \mathrm{~cm}^{-1}\left(v_{\mathrm{C}-\mathrm{OH}}\right)$ showing as evidence the presence of PVA and PCL chains.

\section{Poly(vinyl alcohol)-g-polylactide}

As in precedent structure, grafting was clearly demonstrated in ${ }^{1} \mathrm{H}$ NMR spectra by the presence of the methine proton of the ester linkage between PVA backbone and PLA side chains ( $\alpha$ in Figure 4). This signal at 5.40 ppm was assigned on the basis of analysis of related graft PVA spectra. ${ }^{21,28,30}$ Following assignments were also done: methine proton of non grafted PVA units at $3.87 \mathrm{ppm}$ ( $\gamma$ in Figure 4), methylene protons of PVA backbone at 1.8-2 $\operatorname{ppm}(\beta, \delta$ in Figure 4), methine proton and methyl group of PLA repeating units at $5.16 \mathrm{ppm}$ and $1.45 \mathrm{ppm}$ (a,b in Figure 4), methine proton and methyl group of end-PLA unit at 4.20 ppm and 1.30 ppm (c, $d$ in Figure 4).

In ${ }^{13} \mathrm{C}$ NMR spectra, the connecting methine carbon on the PVA chain appeared at $69.42 \mathrm{ppm}$ ( $\alpha$ in Figure 5). The carbon of the connecting ester group and the carbon of ester group in the PLA side chains appeared at $169.59 \mathrm{ppm}$ and $175.08 \mathrm{ppm}$ respectively (a in Figure 5), methylene signal of PVA backbone $(\beta, \delta$ in Figure 5) appeared at about $39 \mathrm{ppm}$ with very weak intensity in excellent agreement with data reported. ${ }^{21}$ Complete assignment was done in Figure 5.

FTIR spectra of the copolymers showed the main absorption bands at $3490 \mathrm{~cm}^{-1}$ (linked $v_{\mathrm{OH}}$ ) and $1761 \mathrm{~cm}^{-1}\left(v_{\mathrm{OC}=\mathrm{O}}\right)$.

\section{Ability of $\mathrm{MgH}_{2}$ to catalyse the reaction}

Mixtures of PVA and CL or L-LA at $150{ }^{\circ} \mathrm{C}$ for $48 \mathrm{~h}$ gave no detectable amount of copolymers showing that $\mathrm{MgH}_{2}$ catalyst was essential to form PVA macro-initiator for ROP of monomers. Based on the following general reaction:

$$
2 \mathrm{ROH}+\mathrm{MgH}_{2} \rightarrow \mathrm{ROMgOR}+2 \mathrm{H}_{2}
$$

$\mathrm{Mg}$ divalent metal could lead to the possible formation of 2 simultaneous propagating species from 2 adjacent hydroxyl groups of PVA units forming a 6-membered ring ${ }^{26}$ (scheme 1).

Such hypothesis suggested the equation (3) to estimate the theoretical degree of substitution $\left(\mathrm{DS}_{\mathrm{th}}\right)$ of PVA backbone. Comparison between theoretical and experimental degree $\mathrm{DS}_{\exp }$ (equation (1), (5) from NMR) showed that $\mathrm{DS}_{\text {exp }}$ was smaller than $\mathrm{DS}_{\mathrm{th}} / 2$ for all runs (Table 
1,2). Data allowed to conclude that only one propagating species on average, probably resulted from the reaction of $\mathrm{MgH}_{2}$ and hydroxyl groups for steric bulk reasons.

Experimental degree of polymerization $\mathrm{DP}_{\exp }$ (equation (2), (6)) was in a narrow range between 1 to 10 , lower than $\mathrm{DP}_{\text {th }}$ theoretical one (equation (4), (7)).

$\mathrm{M}_{\mathrm{n}}$ of PVA-g-PCL copolymers (runs 4-6 in Table 1) were estimated (equation (8)) from $\mathrm{DP}_{\exp }$ at 83000,143000 and $148000 \mathrm{~g} \mathrm{~mol}^{-1}$ while SEC in chloroform at ambient temperature with polystyrene standards, gave 68000, 124000 and $104000 \mathrm{~g} \mathrm{~mol}^{-1}$ respectively. For PVA-gPLA, $\mathrm{M}_{\mathrm{n}}$ were estimated at 95000, 112000 and $117000 \mathrm{~g} \mathrm{~mol}^{-1}$ (runs 7-9 in Table 2) while SEC gave 65000, 66000 and $86000 \mathrm{~g} \mathrm{~mol}^{-1}$. No satisfactory correlation was noticed for copolymers from other runs in these experimental

conditions. This originated partly in the limited solubility of copolymers and difference in swelling between PVA hydrophilic and PCL hydrophobic blocks.

$\mathrm{DP}_{\text {exp }}$ is dependent on the monomer / $\mathrm{MgH}_{2}$ ratio however it was not increased with high monomer contents (run 1, 2 in Table 1 and 1-5 in Table 2) suggesting a limitation in chain growing during the propagation step.

A possible explanation for this is that, besides intermolecular transesterification frequent in melt process, hydroxyl or alkoxide magnesium end groups of PCL and PLA chains cause backbiting via intramolecular transesterification leading to a $\mathrm{DP}_{\exp }$ decrease. Probably backbiting reactions are enhanced by large number of hydroxyl or alkoxy magnesium end groups and by the reaction temperature. ${ }^{31,32}$ Experimental degree of polymerization lower than theoretical one was also noticed for graft PVA copolymer synthesis in solution with $\mathrm{Sn}(\mathrm{Oct})_{2}$ as catalyst showing the difficulties to control the polymerization totally. ${ }^{19,21}$

\section{Thermal properties}

Thermal properties of copolymers were determinate by DSC. For PVA-g-PCL only one glass transition temperature $\left(\mathrm{T}_{\mathrm{g}}\right)$ and one melting temperature $\left(\mathrm{T}_{\mathrm{m}}\right)$ were observed. $\mathrm{T}_{\mathrm{g}}$ was greater than $\mathrm{T}_{\mathrm{g}}$ of PCL and lower than $\mathrm{T}_{\mathrm{g}}$ of PVA $\left(-65{ }^{\circ} \mathrm{C}\right.$ and $68{ }^{\circ} \mathrm{C}$ respectively) (Table 1$) . \mathrm{T}_{\mathrm{g}}$ varied in about $30{ }^{\circ} \mathrm{C}$ range and it decreased with increasing $\mathrm{DP}_{\exp }$ and $\mathrm{DS}_{\exp }$. Decrease in $\mathrm{T}_{\mathrm{g}}$ was in relation to the increase of free volume and mobility of copolymer chains resulting from the increase of the length and the number of PCL side chains. $\mathrm{T}_{\mathrm{m}}$ was clearly observed for copolymers with highest $\mathrm{DP}_{\exp }$ (run 1-6, Table 1) because longer PCL side chains made easier possible organisation in crystalline phase. Therefore, it can be assumed that PVA and polyester chains were miscible. For PVA-g-PLA, only one $\mathrm{T}_{\mathrm{g}}$ was also observed but it was lower than $\mathrm{T}_{\mathrm{g}}$ of PLA (about $57^{\circ} \mathrm{C}$ ). Moreover, broad melting peak areas were present on a 
wide temperature range about $60{ }^{\circ} \mathrm{C}$ showing probable difficulties for the copolymer to crystallise in one phase (Table 2). It seems that grafting PLA chains strongly restricted the crystallisation of PVA backbone.

\section{Amphiphilic properties of graft copolymers}

Hydrophilic-hydrophobic properties of copolymers were evaluated by wettability and surface energy measurements on cast films from copolymer samples easily soluble in $\mathrm{HCCl}_{3}$ or $\mathrm{THF}$ (Table 3). A regular change of water contact angle $\theta_{\mathrm{H} 2 \mathrm{O}}$ and surface energy $\gamma_{\mathrm{s}}$ from hydrophilic PVA film $\left(54^{\circ}\right.$ and $\left.52.3 \mathrm{~mJ} \mathrm{~m}^{-1}\right)$ to PVA-g-PCL films $\left(78^{\circ}\right.$ and $\left.40.8 \mathrm{~mJ} \mathrm{~m}^{-1}\right)$ and PVA-g-PLA films (84 ${ }^{\circ}$ and $36.4 \mathrm{~mJ} \mathrm{~m}^{-1}$ ) was noticed according to the amount of hydrophobic CL or LA monomer units grafted on the PVA backbone. The increase of $\theta_{\mathrm{H} 2 \mathrm{O}}$ and the decrease of $\gamma_{\mathrm{s}}$, mainly the decrease of $\gamma_{\mathrm{s}}^{\mathrm{p}}$ polar component, according to the increase of $\mathrm{DP}_{\text {exp, }} \mathrm{DS}_{\exp }$ and PCL, PLA (Table 1,2) content, were indicative of the amphiphilic character of copolymers.

These $\theta_{\mathrm{H} 2 \mathrm{O}}$ and $\gamma_{\mathrm{s}}$ optimal values are similar to those of PCL and PLA homopolymers showing that hydrophobic chains were oriented toward the surface of the films.

Hydrophilic-hydrophobic properties were also evaluated via the possible formation of micelle-like particles characterized by the critical micelle concentration (CMC).

It can be in general assumed that for amphiphilic copolymers in a selective solvent below CMC, only molecularly dissolved copolymer, usually as unimers, is present in solution but above CMC multi-molecular micelles are in equilibrium with the unimers.

The report on PVA copolymers as a hydrophilic block for the formation of micelles in an aqueous phase is rare. In this domain, micelles from poly(vinyl alcohol) randomly grafted with hydrophobic methacryloyl groups ${ }^{33}$ and micelles from poly(vinyl alcohol-b-styrene) diblock copolymer were prepared by dialysis against water, ${ }^{34}$ micelles from mixture of PVA with carboxy-ended polybutadiene were formed in aqueous solution by the precipitation method $^{35}$.

From own experiment, it could be observed the formation of micelle-like particles in aqueous solution prepared from dilute solutions of PVA-g-PCL and PVA-g-PLA copolymers in THF followed by slow addition of water and slow evaporation of THF. CMC were measured at 25 ${ }^{\circ} \mathrm{C}$ as the concentration corresponding with the change in slope of the curve of the surface tension of copolymer solutions in water versus the concentration. ${ }^{36} \mathrm{CMC}$ was in $0.5-0.02 \mathrm{~g} / \mathrm{L}$ range and decreased according to the increase of PCL and PLA content (Table 1,2), DP exp and $\mathrm{DS}_{\text {exp }}$ that is the length and the number of hydrophobic chains (Figure 6). Micelle-like 
particles were stable with time up to about $10 \mathrm{~g} / \mathrm{L}$ and resulted from a so-called closed association process based on amphiphilic properties. Higher concentrations led to the formation of viscous hydrogels that progressively and partially separated.

\section{Summary}

The use of $\mathrm{MgH}_{2}$ as catalyst for the formation of PVA macro-initiator for the ROP of CL and LA was established. One propagating alkoxide species resulted from the reaction of $\mathrm{MgH}_{2}$ and hydroxyl groups of PVA backbone. The grafted copolymers were prepared in good yield in melt by adjustment of monomer / PVA ratio and temperature. PVA-g-PCL and PVA-gPLA were characterized by ${ }^{1} \mathrm{H}$ and ${ }^{13} \mathrm{C}$ NMR, IR, SEC, DSC. Grafting of hydrophobic chains on hydrophilic PVA was demonstrated by the variation of wettability and surface energy as well as by the formation of micelle-like particles in aqueous solution. Interest for this method is the use of $\mathrm{MgH}_{2}$ environmental catalyst, absence of solvent and possible recovery of solid material without further operation at the end of the polymerization process. Method could be expanded to other macro-initiators for the synthesis of copolymers to develop new materials particularly in medical sector.

\section{References}

1. Okano, T. Editor. Biorelated polymers and gels: controlled release and applications in biomedical engineering, Academic press: London, 1998.

2. Doi, Y ; Steinbuechel, A. Editors. Biopolymers, Volume 4: Polyesters III. Applications and Commercial Products, Wiley: Weinhein, 2002.

3. Mecerreyes, D.; Jérome, R.; Dubois, P. Adv Polym Sci 1999,147,1.

4. Mecerreyes, D.; Jérome, R. Macromol Chem Phys 1999,200,2581.

5. Albertsson, A-C.; Varma, I.K. Biomacromolecules 2003,4,1466.

6. Zhong, Z.; Dijkstra, P.J.; Birg, C.; Westerhausen, M.; Feijen, J. Macromolecules $2001,34,3863$. 
7. Wang, X.; Liao, K.; Quan, D.; Wu, Q. Macromolecules 2005,38,4611.

8. Stolt, M.; Krasowska, K.; Rutkowska, M.; Janik, H.; Rosling, A.; Soedergard, A. Polym Int $2005,54,362$.

9. Liu, J.; Liu, L. Macromolecules 2004,37,2674.

10. Kricheldorf, H.R. ; Boettcher, C. Makromol Chem Macromol Symp1993,73,47.

11. Deng, X.M. ; Xiong, C.D. ; Cheng, L.M. ; Xu, R.P. J Polym Sci, Part C: Polym Lett $1990,28,411$.

12. Li, S.; Garreau, H.; Pauvert, B.; McGrath, J.; Toniolo, A.; Vert, M. Biomacromolecules $2002,3,525$.

13. Piao, L.; Dai, Z.; Deng, M.; Chen, X.; Jing, X. Polymer 2003,44,2025.

14. Tanzi, M.C.; Verderio, P.; Lampugnani, M.G.; Resnati, M.; Dejana, E.; Sturani, E. J Mater Sci: Mater Med 1994,5,393.

15. Schwach, G.; Coudane, J.; Engel, R.; Vert, M. Polym Bull 1996,37,771.

16. Korhonen, H.; Helminen, A.; Seppala, J.V. Polymer 2001,42,7541.

17. Biela, T.; Duda, A.; Pasch, H.; Rode, K. J Polym Sci, Part A: Polym Chem 2005,43,6116.

18. Tsuji, H.; Nishikawa, M.; Sakamoto, Y.; Itsuno, S. Biomacromolecules 2007,8,1730.

19. Aoi, K.; Aoi, H.; Okada, M. Macromol Chem Phys 2002,203,1018.

20. Onyari, J.M.; Huang, S.J. Polym Prepr, ACS Polym Chem 1996,37,145.

21. Breitenbach, A.; Kissel, T. Polymer 1998,39,3261. 
22. Watanabe, K.; Fujiwa, T.; Isobe, T.; Sagane, H. EP 704470 (1996). Daicel Chem. JP. Chem. Abstr. 1996, 125, 60008t.

23. Kissel, T.; Breitenbach, A.; Jung, T.; Kamm, W. EP 1132416 (2001). Aventis Res. Tech. Chem. Abstr. 2001, 135, 227411d.

24. Owens, D.K.; Wendt, R.C.; J. Appl. Sci. 1969, 13, 1741.

25. Duda, A.; Kowalski, A.; Libiszowski, J.; Penczek, S. Macromol Symp 2005,224,71.

26. Finch, C.A. Editor. Polyvinyl Alcohol Developments; Wiley: Chichester, 1992.

27. Holland, B.J.; Hay, J.N. Polymer 2001,42,6775.

28. Gimenez, V.; Mantecon, A.; Cadiz, V. J Polym Sci, Part A: Polym Chem 1996,34,925.

29. Silverstein, R.M.; Webster, F.X. Spectrometric Identification of Organic compounds. $6^{\text {th }}$ edition; Wiley: New York, 1998.

30. Carlotti, S.J.; Giani-Beaune, O.; Schué, F. J Appl Polym Sci 2001,80,142.

31. Mc Neill, I.C.; Leiper, H.A. Polym Degrad Stab 1985,11,309.

32. Jamshidi, K.; Hyon, S.H.; Ikada, Y. Polymer 1988,29,2229.

33. Cavalieri, F.; Chiessi, E. Paradossi, G. Soft Matter 2007,3,718.

34. Li, G.H.; Chon, C.G. Colloid Polym Sci 2005,283,946.

35. Zhang, Y.; Jiang, M.; Zhao, J.; Zhou, J.; Chen, D. Macromolecules 2004,37,1537.

36. Riess, G. Prog Polym Sci 2003,28,1107. 


\section{List of Tables and Figures}

Table 1. Properties of poly(vinyl alcohol)-g-poly( $\varepsilon$-caprolactone) (PVA-g-PCL) from meltsynthesis using $\mathrm{MgH}_{2}$ as catalyst

Table 2. Properties of poly(vinyl alcohol)-g-poly( $\varepsilon$-caprolactone) (PVA-g-PLA) from meltsynthesis using $\mathrm{MgH}_{2}$ as catalyst

Table 3. Wettability and surface energy of poly(vinyl alcohol)-g-poly(e-caprolactone) films and poly(vinyl alcohol)-g-polylactide films

Scheme 1. Possible activated species

Figure 1. Conversion $\%$ of monomer versus time for the copolymerization of $\varepsilon$-CL with PVA (•) (run 5 in Table 1) and L-LA with PVA $\left(^{\circ}\right.$ ) (run 3 in Table 2). (no solvent, under argon, temperature $150^{\circ} \mathrm{C}$ )

Figure 2. $400 \mathrm{MHz}{ }^{1} \mathrm{H}$ NMR spectrum of PVA-g-PCL from melt-synthesis using $\mathrm{MgH}_{2}$ as catalyst $\left(25^{\circ} \mathrm{C}\right.$, solvent $\left.\mathrm{CDCl}_{3}\right)$

Figure 3. $100 \mathrm{MHz}{ }^{13} \mathrm{C}$ NMR spectrum of PVA-g-PCL from melt-synthesis using $\mathrm{MgH}_{2}$ as catalyst $\left(25^{\circ} \mathrm{C}\right.$, solvent $\left.\mathrm{CDCl}_{3}\right)$

Figure 4. $400 \mathrm{MHz}{ }^{1} \mathrm{H}$ NMR spectrum of PVA-g-PLA from melt-synthesis using $\mathrm{MgH}_{2}$ as catalyst $\left(25^{\circ} \mathrm{C}\right.$, solvent $\left.\mathrm{CDCl}_{3}\right)$

Figure 5. $100 \mathrm{MHz}{ }^{13} \mathrm{C}$ NMR spectrum of PVA-g-PLA from melt-synthesis using $\mathrm{MgH}_{2}$ as catalyst $\left(25^{\circ} \mathrm{C}\right.$, solvent $\left.\mathrm{CDCl}_{3}\right)$

Figure 6. Surface tension of aqueous solutions of grafted copolymers versus concentration : PVA-g-PCL, a), b), c) respectively run 4, 5, 6 in Table 1 and PVA-g-PLA, d), e), f) respectively run $7,8,9$ in Table 2 